\title{
Ultrasonography changes at quadriceps tendon donor site in anterior cruciate ligament reconstruction. Is it consistent with regeneration?
}

\author{
D. Nalla ${ }^{1}$, S. Kumar Nema1', D. Barathi², G. Balaji ${ }^{1}$ \\ 1 Department of Orthopedics, Jawaharlal Institute Of Postgraduate Medical Education and Research Pondicherry \\ India \\ 2 Department of Radiodiagnosis, Jawaharlal Institute of Postgraduate Medical Education and Research, \\ Pondicherry, India
}

\section{CORRESPONDING AUTHOR: \\ Sandeep Kumar Nema \\ Department of Orthopedics \\ Jawaharlal Institute Of Postgraduate \\ Medical Education and Research \\ Pondicherry India \\ E-mail: drsandeepnema@gmail.com}

DOI:

10.32098/mltj.01.2019.11

\begin{abstract}
SUMMARY
Background. Researchers have investigated changes at the donor site for hamstrings and patellar tendons to be consistent with regeneration in anterior cruciate ligament reconstruction (ACLR). Recently free quadriceps tendon has emerged as a potential autograft for ACLR. The objective of this study was to investigate the changes at the quadriceps tendon (QT) donor site after primary ACLR by serial ultrasound. Methods. The donor site was studied preoperatively, 2 weeks and 6 months postoperatively by serial ultrasound in 16 patients who underwent ACLR using QT autograft. QT structure, length, width, and thickness were studied at 1,3 and $5 \mathrm{~cm}$ from the superior pole of the patella. Results. There was no difference in thickness of QT preoperatively and 6 months postoperatively. But the mean thickness of QT changed postoperatively from $0.9,1.0$ and $1.0 \mathrm{~mm}$ at 2 weeks to $5.1,4.9$ and $4.6 \mathrm{~mm}$ at 6 months, which was significant. There was a difference in mean width at 6 months postoperatively $(22.8,21.5$ and $20.9 \mathrm{~mm})$ compared to preoperative $(24.3,24.6$ and $23.5 \mathrm{~mm})$ and 2 weeks postoperative $(24.4,24.0$ and $23.6 \mathrm{~mm})$ measurements. There was no change in length (L) of the QT between times frames. The central third of QT regained its uniform echogenicity and punctate appearance 6 months postoperatively in all cases. Conclusion. The ultrasonography findings at the donor site are consistent with regeneration, but further imaging and histological examination are required to verify morphology and quality of regenerate.
\end{abstract}

\section{KEY WORDS}

ultrasonography; anterior cruciate ligament reconstruction; regeneration; tendons

\section{INTRODUCTION}

Regeneration of patellar and hamstrings tendons to various extents has previously been reported (1-4). However, the quality of regenerate is debatable across published literature $(5,6)$. Free quadriceps tendon $(\mathrm{QT})$ has emerged as a potential autograft for anterior cruciate ligament reconstruction (ACLR). To the best of our knowledge, no prospective study has investigated changes occurring at the QT donor site after ACLR. The aim of this study was to investigate the changes occurring at the QT donor site after primary ACLR by serial ultrasound.

\section{MATERIALS AND METHODS}

This prospective cohort study was conducted from Jan 2016 to Dec 2017 at Jawaharlal Institute of Postgraduate Medical Education and Research (JIPMER), Pondicherry, India. The study was approved by the institute's review board for 
human studies. The study has been conducted ethically according to set international standards and meets the ethical standards of the journal (7). Patients operated for ACLR using QT graft between 18 to 60 years were included in the study. Patients with connective tissue disorder, past surgery, or scar to the operated knee, interfering with the ultrasonographic assessment of the QT, were excluded from the study.

\section{Operative procedure}

The central third of QT autograft was harvested through $8-10 \mathrm{~cm}$ incision directly over it with the knee in 90 degrees of flexion. Peritenon was split in the midline and retracted on either side to expose the central third of QT. A No. 15 scalpel blade was used to harvest the central third of the QT measuring 6 x $10 \times 7 \mathrm{~mm}$ (length $\mathrm{x}$ width $\mathrm{x}$ depth) from the superior pole of the patella to the musculotendinous junction (figure 1). Precautions were taken to prevent a breach of the floor at the donor site. The floor was repaired whenever it breached with absorbable suture 3-0 (PDS*II Ethicon New Jersey USA). The surgical defect created after harvest in the central third of QT was left un-sutured. The peritenon was sutured over the defect. Skin and subcutaneous tissue were approximated in layers.

\section{Post-operative rehabilitation}

All the patients followed standard ACL rehabilitation protocol (8).

\section{Ultrasonography examination}

The ultrasonographic assessments were done preoperatively, 2 weeks and 6 months postoperatively. A 12-15 Range megahertz $(\mathrm{MHz})$ real-time linear array transducer

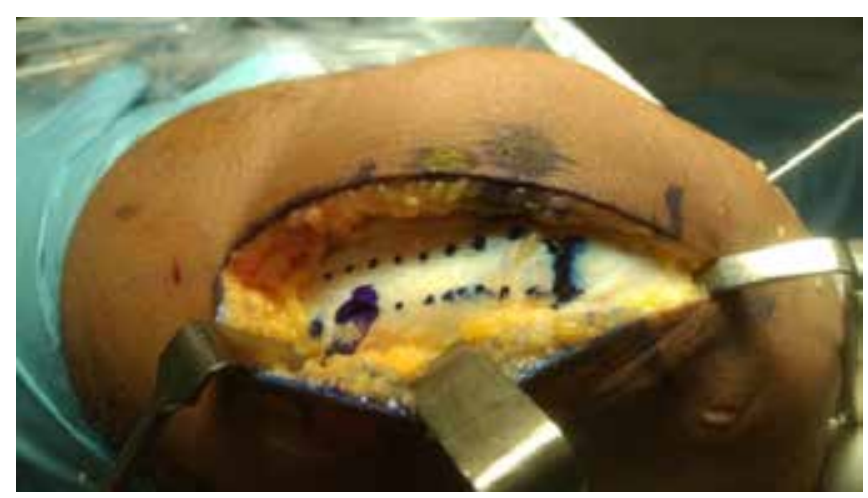

Figure 1 - Picture showing marking of the central one third of QT during operation.
(Acuson S3000 Siemens Munich, Germany) was used to scan the knee. The knee was positioned in 90-degree flexion to bring QT superficial and easily visible during the ultrasonographic examination. The tendon structure that included echogenicity, fiber alignment, edges, and paratenon were imaged in the sagittal and axial views. The ultrasonographic technique of panoramic imaging was used in assessing the length of the tendon. Tendon length (LT) was measured in the sagittal plane from the tendon's attachment on the superior pole of the patella, to the most distal aspect of the rectus femoris muscle (figure 2 ). The width (W) and thickness (T) of the QT were measured in the axial plane at 1,3 and $5 \mathrm{~cm}$ from the superior pole of the patella (figure 3). Thickness was measured at central $10 \mathrm{~mm}$ of the QT. The width was measured from the most medial to the lateral portion of the imaged QT.

On ultrasonographic imaging at 2 weeks and 6 months, the structure exhibiting the magic angle phenomenon at the donor site of QT was considered as tendon tissue. The anatomical structures such as ligaments, tendons, and nerves exhibit magic angle phenomenon widely known as anisometry on ultrasonography. A variation in the angle of interrogating beams produced by the transducer of the ultrasound machine changes the echogenic behavior of these structures. The reflected sound energy is greatest when the interrogating beams are perpendicular to the tendons. This gives the tendon its typical echogenic appearance on ultrasound (9). The structure and parameters vide supra of that tissue were compared between time frames. All the patients were examined by the same author (DB) to ensure a uniform evaluation.

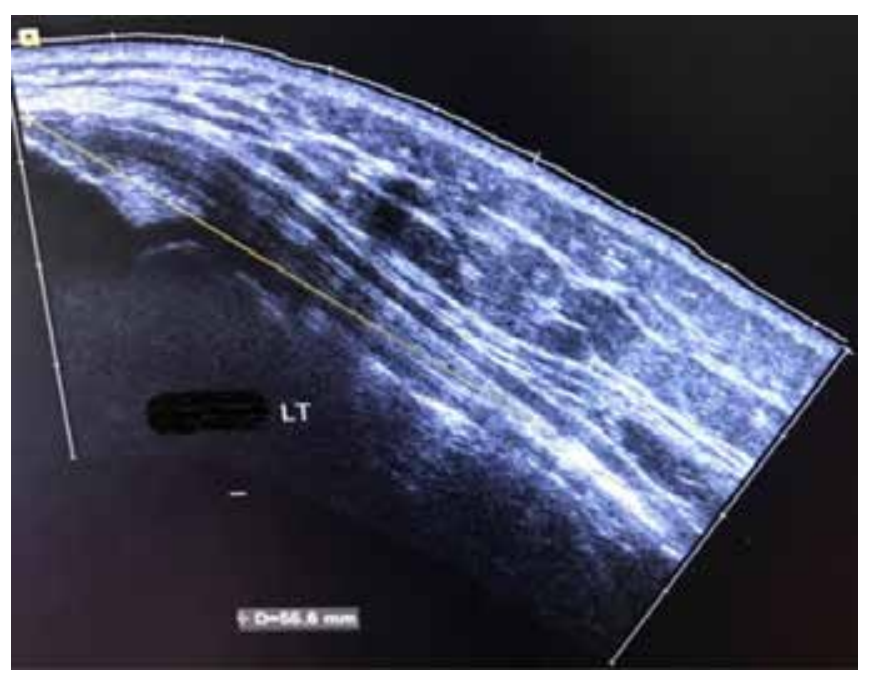

Figure 2 - Sagittal view on ultrasound showing measurement of the QT length (LT). 


\section{Statistical analysis}

Statistical analysis was done using software for windows statistical package for social sciences version 19 (SPSS) (IBM Corporation). The distribution of data on categorical variables (gender, occupation, mode of injury, BMI and limb involved) was expressed as frequency and percentage. The data on discrete / continuous variables (age, height, weight, length, width, and thickness of the tendon) were expressed as mean with standard deviation "or" median range. The comparison of the continuous variables with the categorical variables was analyzed by using Independent Student t-test. The comparison of the relationship between two independent variables was done using correlation analysis test. The changes in the continuous outcome variables at different time points were analyzed by using repeated measures ANOVA. A p-value of less than 0.05 was considered to be statistically significant.

\section{RESULTS}

16 patients were recruited into the study and none were lost to follow-up. The demographic outcomes are described in table I. There were no smokers or alcoholics in the group studied. There was no correlation between BMI and extent of increase in thickness of the tendon ( $\mathrm{Q}=-0.27, \mathrm{p}=0.92$ ). There was no correlation between age and average difference in thickness and width of the tendon postoperatively at 2 weeks and at 6 months $(\varrho=0.26, p=0.314$; and $\varrho=$ $-0.167, \mathrm{p}=0.538$, respectively).

Preoperative ultrasonographic outcomes. QT revealed the linear echogenic structure and magic angle phenomenon on preoperative imaging. The tendon fibers were found to be arranged in echogenic, longitudinal pattern in sagittal views (figure 2 ). The axial view demonstrated punc-
Table I - Demographic outcomes.

\begin{tabular}{|c|c|}
\hline Parameter & Outcome \\
\hline $\begin{array}{l}\text { number of patients at final } \\
\text { evaluation }(n)\end{array}$ & 16 \\
\hline mean age (years) & $27 \pm 5.6$ range $(19-38)$ \\
\hline gender & 13 males, 3 females \\
\hline side involved & right 9 , left 7 \\
\hline occupation & $\begin{array}{l}1 \text {, student } 18.75 \% \\
2 \text {, agricultural laborer } 43.75 \% \\
3 \text {, professionals } 18.75 \% \\
\text { 4, sports person } 6.25 \% \\
5 \text {, house wife } 12.5 \% \\
6 \text {, others } 0 \%\end{array}$ \\
\hline mode of injury & $\begin{array}{l}1 \text {, sports related injuries } 12.5 \% \\
2 \text {, road traffic accidents } 87.5 \% \\
3 \text {, others } 0 \%\end{array}$ \\
\hline mean height $(\mathrm{cm})$ & $\begin{array}{l}1, \text { male } 156.85 \pm 5.91 \\
2, \text { female } 154.67 \pm 6.11\end{array}$ \\
\hline mean weight $(\mathrm{kg})$ & $\begin{array}{l}1, \text { male } 68.23 \pm 8.36 \\
2, \text { female } 58.67 \pm 14.05\end{array}$ \\
\hline body mass index (BMI) & $\begin{array}{l}\text { 1, underweight } 0 \% \\
2 \text {, normal weight } 31.25 \% \\
3 \text {, overweight } 56.25 \% \\
4 \text {, obese } 12.5 \%\end{array}$ \\
\hline
\end{tabular}

tate appearance and an oval cross section of the QT. The edges were regular and echogenicity was uniform in both the views. The surrounding peritenon was found to be a thick hyperechoic line surrounding the tendon in both the views (figure 3 ).

Postoperative ultrasonographic outcomes. The donor site was found to be hypoechogenic because of the absence of central third of the tendon and tissue edema at 2 weeks
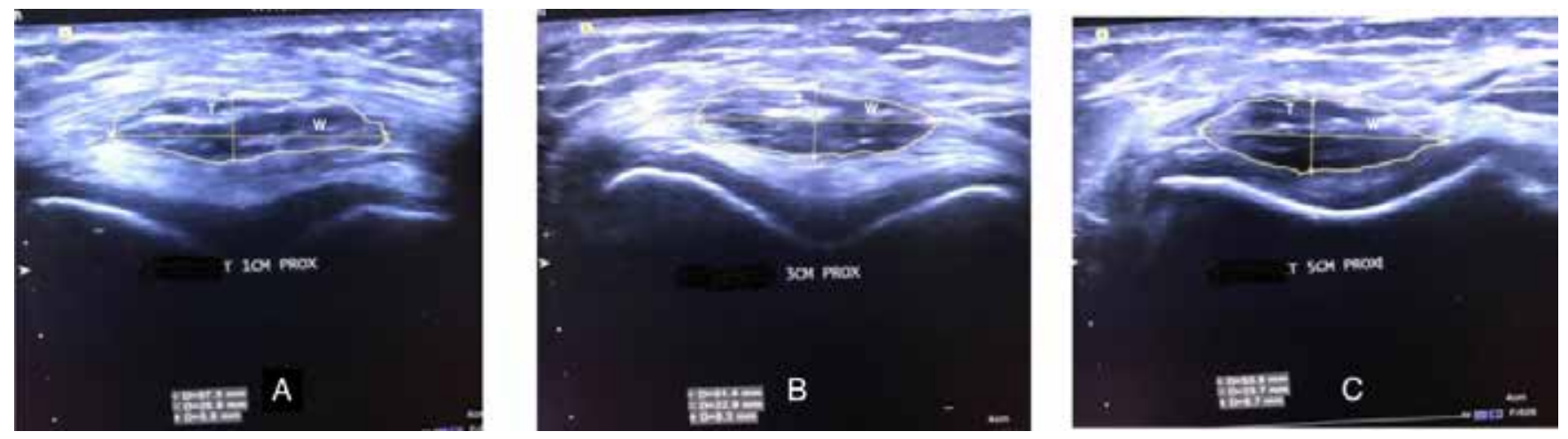

Figure 3 - Axial view of the QT showing thickness (T) and width (W) preoperatively at $1 \mathrm{~cm}(\mathbf{A}), 3 \mathrm{~cm}(\mathbf{B})$, and $5 \mathrm{~cm}(\mathbf{C})$ proximal to the superior pole of the patella. 
postoperatively (figure 4). The central third of QT regained its uniform echogenicity in both the views and punctate appearance in axial views in all the cases at the end of 6 months (figure 5). However, the edges were irregular. The central third QT regained its potential to exhibit magic angle phenomenon.

A summary of measurable outcomes of length, width and thickness at various time frames at the QT donor site on ultrasonography assessment is given in table II. The mean length of the QT measured preoperatively, 2 weeks and 6 months postoperatively were $71.5 \pm 9.11 \mathrm{~mm}, 71.0 \pm 8.7 \mathrm{~mm}$, and $71.46 \pm 8.96 \mathrm{~mm}$ respectively in males, and $56.43 \pm 7.27 \mathrm{~mm}, 56.53$ $\pm 7.0 \mathrm{~mm}$, and $56.86 \pm 6.95$ respectively in females. A repeated measure (within the subjects) ANOVA was performed with time-related to the procedure as an independent variable and length, width and thickness at 1,3 and $5 \mathrm{~cm}$ proximal to the superior pole of the patella as the dependent variables (table II).
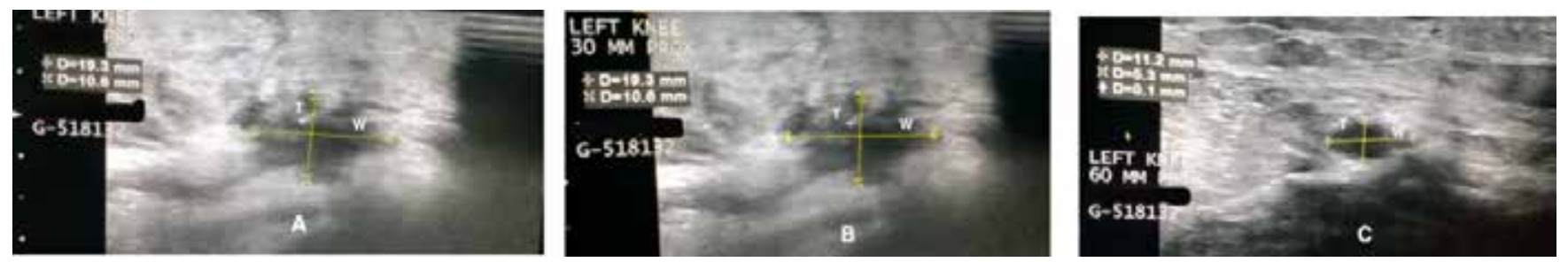

Figure 4 - Axial view of the QT showing thickness (T) and width (W) 2 weeks postoperatively at $1 \mathrm{~cm}(\mathbf{A}), 3 \mathrm{~cm}(\mathbf{B})$, and $5 \mathrm{~cm}(\mathbf{C})$ proximal to the superior pole of the patella.
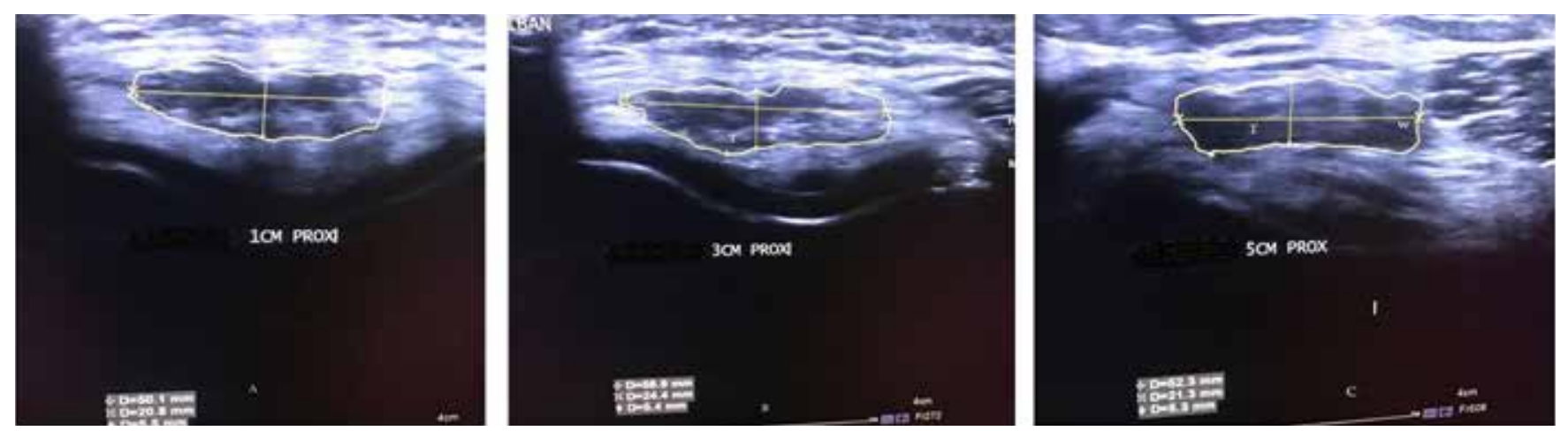

Figure 5 - Axial view of the QT showing thickness (T) and width (W) 6 months postoperatively at $1 \mathrm{~cm}(A), 3 \mathrm{~cm}(B)$, and $5 \mathrm{~cm}(C)$ proximal to the superior pole of the patella

Table II - Ultrasonography measurable outcomes.

\begin{tabular}{|c|c|c|c|c|}
\hline Parameter & $\begin{array}{l}\text { pre-operative } \\
\text { ultrasonography } \\
\text { assessments in } \mathrm{mm}\end{array}$ & $\begin{array}{l}\text { ultrasonography } \\
\text { assessments at } 2 \text { weeks }\end{array}$ & $\begin{array}{l}\text { ultrasonography } \\
\text { assessments at } 6 \text { months }\end{array}$ & repeated measures ANOVA $^{1}$ \\
\hline \multicolumn{5}{|l|}{ width } \\
\hline $1 \mathrm{~cm}$ & $24.3 \pm 3.83$ & $24.41 \pm 3.66$ & $22.8 \pm 3.17$ & $\mathrm{~F}(2,30)=4.45 ; \mathrm{p}<0.05$ \\
\hline $3 \mathrm{~cm}$ & $24.6 \pm 3.66$ & $24.03 \pm 3.06$ & $21.5 \pm 4.08$ & $\mathrm{~F}(2,30)=9.85 ; \mathrm{p}<0.05$ \\
\hline \multicolumn{5}{|l|}{ thickness } \\
\hline $1 \mathrm{~cm}$ & $5.3 \pm 0.59$ & $0.9 \pm 0.08$ & $5.17 \pm 1.14$ & $F(2,30)=45.45 ; p<0.05$ \\
\hline $3 \mathrm{~cm}$ & $5.1 \pm 0.70$ & $1.0 . \pm 0.11$ & $4.95 \pm 0.97$ & $\mathrm{~F}(2,30)=210.93 ; \mathrm{p}<0.05$ \\
\hline $5 \mathrm{~cm}$ & $4.9 \pm 58$ & $1.04 \pm 0.21$ & $4.61 \pm 0.73$ & $\mathrm{~F}(2,30)=319.42 ; \mathrm{p}<0.05$ \\
\hline
\end{tabular}

${ }^{1}$ Analysis of variance. 
The results of the parameters revealed:

1. No difference in length of the QT between time frames (table II);

2. A significant difference in width and thickness of the QT between time frames. (table II);

Post hoc analysis (Bonferonni) was performed for width and thickness.

The findings of analysis revealed:

1. A significant difference in width of QT at 6 months postoperatively and other time frames (preoperatively and 2 weeks postoperatively);

2. A significant difference in thickness of the central third QT at 2 weeks postoperatively and preoperatively;

3. No difference in thickness of the central third QT preoperatively and at 6 months postoperatively.

We found no significant correlation between the decrease in the width of the QT and the extent of increase in the thickness of the central third QT at 1,3 and $5 \mathrm{~cm}$ proximal to the superior pole of the patella according to Spearman's Rho correlation test $(p=0.62)$. There was no difference in the change of the QT thickness between right and left sides. There was no difference in the change of the QT thickness between the genders.

\section{DISCUSSION}

The results of this study demonstrate no difference in thickness of the central third QT donor site preoperatively and 6 months postoperatively on serial ultrasonographic assessments. The regaining of thickness and fibrillary structure at the central third donor site at 6 months postoperatively has four possible explanations.

1. The QT might have regenerated and the new tendon tissue filled the central third QT donor site;

2. A tissue other than the tendon tissue with similar echogenicity on ultrasonography to the QT filled the surgical defect at the donor site;

3. Residual QT fibers got hypertrophied and filled the surgical defect;

4. The QT healed by the adhesion of residual fibers from either side because there was a slight decrease in the width of the QT at 6 months.

The possibility of residual fibers of the QT healing from either side of the surgical defect at the donor site, giving a spurious outcome of the increased thickness in the central one-third of the tendon is remote. The decrease in width at 6 months after operation measured proximal to the superior pole of the patella was not more than $5 \mathrm{~mm}$, where- as the surgical defect created was always equal to or more than $10 \mathrm{~mm}$. There was no statistical correlation between the decrease in the width and increase in the thickness of the tendon proximal to the superior pole of the patella. A compensatory hypertrophy of the tendon has not been demonstrated by studies that assessed regeneration of hamstrings tendons by imaging and histology $(10,11)$. Further, there was a slight decrease in the width of the QT at 6 months post-operative.

Papendrea et al. studied changes at the hamstrings donor site before and after ACLR. The investigators imaged the donor site by ultrasound before and after ACLR up to 2 years (11). They reported similar echogenicity of the hamstrings tendons at the donor site before and after 6 months of harvest. This study imaged the changes at the QT donor site preoperatively, 2 weeks and 6 months postoperatively. The imaging was easy to perform preoperatively and 6 months postoperatively, but was difficult at 2 weeks post-operative due to the presence of artifacts. On ultrasonic evaluation at 6 months, the QT regained its uniformity and fibrillary texture. It demonstrated slightly hypoechoic with few hyperechogenic areas compared to evaluation before the operation.

We choose to scan at 6 months after operation based on the findings of regeneration reported by the investigators vide supra. Studies have investigated changes at the hamstrings donor site utilizing CT and MRI, and have reported it to be consistent with regeneration $(1,12-15)$. Studies have investigated the quality of regenerate at the donor site of hamstrings and patellar tendons. The data reported in these studies are conflicting (16-17). Stevanović et al. investigated regeneration at the hamstrings donor site after ACLR using clinical and ultrasound examination, biopsies and histological tests (18). The investigators demonstrated regeneration in $72 \%$ of cases. The microscopic and histological examination of the regenerated tendon was similar to normal anatomy. They could successfully use regenerated tissue for medial patellofemoral reconstruction in one of their cases. The ultrasonographic findings of hematoma with low echogenicity at 2 weeks postoperatively and uniform echotexture of hamstrings donor site at 6 months demonstrating regeneration in the study of investigators vide supra are in close resemblance to findings of our study. The mean duration of changes consistent with regeneration at QT donor site in our study was 6 months, which is less compared to the studies that have investigated hamstrings and patellar tendon regeneration $(1,11,19)$. The peritenon was carefully incised and repaired during the process of graft harvest in this study. Studies have investigated the role of epitenon and endotenon in regeneration (20). We hypothesize that a thick, well-formed peritenon of the QT might have taken a shorter time for regeneration. We did 
not use the surgical drain in our study which permitted a hematoma to lay a scaffold for tissue regeneration.

Limitations of the study. The main limitations of this study were a small sample size and a short follow-up. The outcomes evaluated using ultrasound were subjective and

\section{REFERENCES}

1. Åhlén M, Lidén M, Bovaller Å, Sernert N, Kartus J. Bilateral Magnetic Resonance Imaging and Functional Assessment of the Semitendinosus and Gracilis Tendons a Minimum of 6 Years After Ipsilateral Harvest for Anterior Cruciate Ligament Reconstruction. Am J Sports Med 2012; 40(8):1735-1741.

2. Åhlén M, Lidén M, Movin T, Papadogiannakis N, Rostgård-Christensen L, Kartus J. Histological Evaluation of Regenerated Semitendinosus Tendon a Minimum of 6 Years After Harvest for Anterior Cruciate Ligament Reconstruction. Orthop J Sports Med 2014; 2(9):232596711455027.

3. Kartus J, Stener S, Lindahl S, Eriksson BI, Karlsson J. Ipsi-or contralateral patellar tendon graft in anterior cruciate ligament revision surgery. Am J Sports Med 1998; 26(4):499-504.

4. Lidén M, Movin T, Ejerhed L, Papadogiannakis N, Blomén E, Hultenby K, et al. A Histological and Ultrastructural Evaluation of the Patellar Tendon 10 Years after Reharvesting its Central Third. Am J Sports Med 2008; 36(4):781-788.

5. Stener S, Ejerhed L, Movin T, Sernert N, Papadogiannakis N, Kartus J. The reharvested patellar tendon has the potential for ligamentization when used for anterior cruciate ligament revision surgery. Knee Surg Sports Traumatol Arthrosc 2012; 20(6):1168-1174.

6. O'Shea JJ, Shelbourne KD. Anterior cruciate ligament reconstruction with a reharvested bone-patellar tendon-bone graft. Am J Sports Med 2002; 30(2):208-213.

7. Padulo J, Oliva F, Frizziero A, Maffulli N. Muscles, Ligaments and Tendons Journal - Basic principles and recommendations in clinical and field science research: 2016 update. MLTJ 2016; 6(1):1-5.

8. Phillips BB, Mihalko MJ. Arthroscopy of the lower extremity In: Canale ST, Beaty JH editors. Campbell's operative orthopedics, 12th edn. Philadelphia PA: Elsevier Mosby; 2013:2433.

9. Chang A, Miller TT. Imaging of Tendons. Sports Health 2009; 1(4):293-300.

10. Simionian PT, Harrison SD, Cooley VJ, et al: Assessment of morbidity of semitendinous and gracilis tendon harvest for ACL reconstruction. J Knee Surg 1997; 10:54-59.

11. Papandrea P, Vulpiani MC, Ferretti A, Conteduca F. Regeneration of the semitendinosus tendon harvested for anterior cruciate ligament reconstruction. Evaluation using ultrasonography. Am J Sports Med 2000; 28(4):556-561. evaluator dependent. Future studies investigating changes at the QT donor site by MRI to characterize morphological changes are required to confirm findings of this study. Biopsy and histological examination of the QT donor site can further reveal the quality of regenerate.

12. Nakamae A, Deie M, Yasumoto M, Adachi N, Kobayashi K, Yasunaga $\mathrm{Y}$, et al. Three-dimensional computed tomography imaging evidence of regeneration of the semitendinosus tendon harvested for anterior cruciate ligament reconstruction: a comparison with hamstring muscle strength. J Comput Assist Tomogr 2005; 29(2):241-245.

13. Tadokoro K, Matsui N, Yagi M, Kuroda R, Kurosaka M, Yoshiya S. Evaluation of Hamstring Strength and Tendon Regrowth after Harvesting for Anterior Cruciate Ligament Reconstruction. Am J Sports Med 2004; 32(7):1644-1650.

14. Rispoli DM, Sanders TG, Miller MD, Morrison WB. Magnetic resonance imaging at different time periods following hamstring harvest for anterior cruciate ligament reconstruction. Arthrosc J Arthrosc Relat Surg 2001; 17(1):2-8.

15. Cross MJ, Roger G, Kujawa P, Anderson IF. Regeneration of the semitendinosus and gracilis tendons following their transection for repair of the anterior cruciate ligament. Am J Sports Med 1992; 20(2):221-223.

16. Okahashi K, Sugimoto K, Iwai M, Oshima M, Samma M, Fujisawa Y, et al. Regeneration of the hamstring tendons after harvesting for arthroscopic anterior cruciate ligament reconstruction: a histological study in 11 patients. Knee Surg Sports Traumatol Arthrosc 2006; 14(6):542-545.

17. Svensson M, Kartus J, Christensen LR, Movin T, Papadogiannakis N, Karlsson J. A long-term serial histological evaluation of the patellar tendon in humans after harvesting its central third. Knee Surg Sports Traumatol Arthrosc 2005; 13(5):398-404.

18. Stevanović V, Blagojević Z, Petković A, Glišić M, Sopta J, Nikolić V, Milisavljević M. Semitendinosus tendon regeneration after anterior cruciate ligament reconstruction: can we use it twice? Int Orthop 2013; 37(12):2475-2481.

19. Eriksson K, Kindblom LG, Hamberg P, Larsson H, Wredmark T. The semitendinosus tendon regenerates after resection: a morphologic and MRI analysis in 6 patients after resection for anterior cruciate ligament reconstruction. Acta Orthop Scand 2001; 72(4):379-384.

20. Abrahamsson SO, Lundborg G, Lohmander LS. Restoration of the Injured Flexor Tendon Surface: A Possible Role for Endotenon Cells: A morphological study of the rabbit tendon in vivo. J Hand Surg 1992; 17(5):553-560. 